\title{
FAKTOR-FAKTOR YANG MEMPENGARUHI WISATAWAN BERKUNJUNG KE MUSEUM TEKSTIL JAKARTA
}

\author{
Dewanta Facrureza ${ }^{1,}$ Cindy Vinessia ${ }^{2}$ \\ Program Studi Perhotelan, Fakultas Ilmu Sosial Dan Humaniora Akademi Pariwisata Bunda Mulia, Indonesia \\ Email: dfacrureza@bundamulia.ac.id
}

\begin{abstract}
Abstrak
Penelitian ini bertujuan untuk mengetahui faktor-faktor yang mana yang mempengaruhi wisatawan untuk berkunjung ke Museum Tekstil Jakarta. Jenis penelitian yang digunakan adalah asosiatif dengan pendekatan kuantitatif. Penelitian ini menggunakan teknik pengambilan sampel purposive sampling, dengan kriteria sampel konsumen yang sudah pernah berkunjung ke Museum Tekstil Jakarta. Sampel dalam penelitian ini sebanyak 100 responden. Penelitian ini menggunakan uji validitas, uji reliabilitas,uji normalitas,uji heteroskedastisitas,uji regresi berganda, uji $\mathrm{T}$, uji $\mathrm{F}$ dan koefisien determinasi. Hasil analisis dari uji dimana penelitian telah lakukan dapat disimpulkan bahwa 4 dimensi yang diuji, yaitu Profil Wisatawan/Tourist Profile, informasi untuk dilakukannya Perjalanan/Travel Awareness bagi wisatawan, Karakteristik Perjalanan/Trip Features, serta Sumber Daya dan Karakteristik Daerah Tujuan/Resources and Characteristic of Destination memiliki pengaruh sebesar 60,8\% dan secara simultan mempunyai pengaruh signifikan terhadap Keputusan Berkunjung.
\end{abstract}

Kata Kunci: Faktor-Faktor Berkunjung, Keputusan Berkunjung, Museum Tekstil

\begin{abstract}
The purpose of this study is to determine which factors can influence tourists visiting the Jakarta Tekstil Museum. The type of research used is associative with a quantitative approach. This study uses a purposive sampling technique, with a sample of consumers who have visited Jakarta Tekstil Museum. The sample in this study were 100 respondents. This research uses validity test, reliability test, normality test, heteroscedasticity test, multiple regression test, $T$ test, $F$ test and coefficient of determination. The results of the analysis of the tests that have been carried out can be concluded that the 4 dimensions tested, namely the Tourist Profile,Travel Awareness, Trip Features, and Resources and Characteristics of Destination have influenceof60.8\% and simultaneously has asignificant influence on the Visit Decision.
\end{abstract}

Keywords: Visitting factors, Visiting Decisions, Tekstil Museum. 


\section{INTRODUCTION}

Museum sendiri merupakan salah satu daya tarik wisata yang menarik untuk dikunjungi dan dapa tmemberikan informasi serta edukasi tentang sejarah dan budaya dari kehidupan masa lampau. Mendengar kata museum dengan sendirinya mengingatkankitadenganbenda- benda] kuno atau benda bersejarah yang terikatdengan peradaban maupun budaya di masa lalu. Seringkali museum dianggap sebaga itempat yang sangat membosankan karena hanya berisikan barang kuno, selain itu terlepasdari image museum sendiri yang terkesan statis dan konservatif dan beberapa bangungan museum yang menyeramkan dan terkesan angker. Dengan adanya pandangan yang seperti ini dapat menyebabkan menurunnya tingkat kunjungan masyarakat. Mengingat masih kurangnya minat wisatawan untuk berkunjung ke museum, peneliti akan mengambil Museum Tekstil sebagai objek penelitian.

Berikut data kunjungan Museum Tekstil Jakarta :

\begin{tabular}{|l|c|c|c|}
\hline \multicolumn{1}{|c|}{ Uraian } & $\begin{array}{c}\text { Tahun } \\
2017\end{array}$ & $\begin{array}{c}\text { Tathun } \\
2018\end{array}$ & $\begin{array}{l}\text { Tahun } \\
2019\end{array}$ \\
\hline $\begin{array}{l}\text { Jumlah } \\
\text { Pengunjung } \\
\text { Museum } \\
\text { Tekstil } \\
\text { Jakarta }\end{array}$ & 50.038 & 45.375 & 38.087 \\
& & & \\
\hline
\end{tabular}

Sumber Data : Pemprov DKI Jakarta, 2019

Berdasarkan data 3 tahun terakhir tersebut dapat dilihat bahwa terjadi penurunan jumla hkunjungan ke Museum Tekstil dari tahun ketahun serta tingkat kunjungan yang lebih rendah jika dibandingkan dengan beberapa museum lainnya.

Faktor-faktor yang mempengaruhi perjalanan wisatawan harus dipahami agar dapat mengetahui factor apa saja yang memiliki pengaruh paling besar sehingga dapat dimaksimalkan, serta factor apa saja yang harus diperbaiki. Faktor-faktor yang mempengaruhi perjalanan wisata menurut Foster, 1985, yaitu adalah profil wisatawan, pengetahuan untuk melakukan perjalanan, karakteristik perjalanan, serta sumberdaya dan karakteristik daerah tujuan.

Faktor-faktor utama yang mempengaruhi perjalanan wisata adalah sebagai berikut Foster, 1985 (dalam Kusuma Dewi, 2018):

1. Profil Wisatawan (tourist Profile) Profil wisatawan dapat dikelompokan menjadi 2 (dua) kategori, yaitu:

a. Karakteristik social ekonomi wisatawan (sosio- economic characteristic) yang terdapat di dalamnya adalah umur, pendidikan, tingkat pendapatan.

b. Karakteristik tingkah laku (behavioural characteristic) yang terdapat di dalamnya adalah , motivasi, sertasikap dan keinginan wisatawan.

2. Pengetahuan untuk melakukan perjalanan (travel awareness) yang terdapat di dalamnya adalah informasi tentang daerah tujuan wisata, ketersediaan fasilitas, ketersediaan pelayanan.

3. Karakteristik perjalanan (trip features) yang terdapat di dalamnya adalah jarak, waktu tinggal di daerah tujuan, biaya, waktu perjalanan.

4. Sumberdaya dan karakteristik daerah tujuan (resources and characteristic of destination) yang terdapat di dalamnya adalah jenis atraksi, akomodasi,

5. Ketersediaan dan kualitasfasilitas, ketersediaan dan kualitas pelayanan, dan kondisi lingkungan.

Penelitian ini harus diangkat agar pihak pengelola Museum Teksti lmemahami faktor 
mana yang paling mempengaruhi wisatawan untuk berkunjung. Selain itu,

penelitian ini dapat digunakan oleh pihak pengelola museum sebagai acuan untuk meningkatkan kualitasnya sehingga dapa tmeningkatkan kunjungan wisatawan.

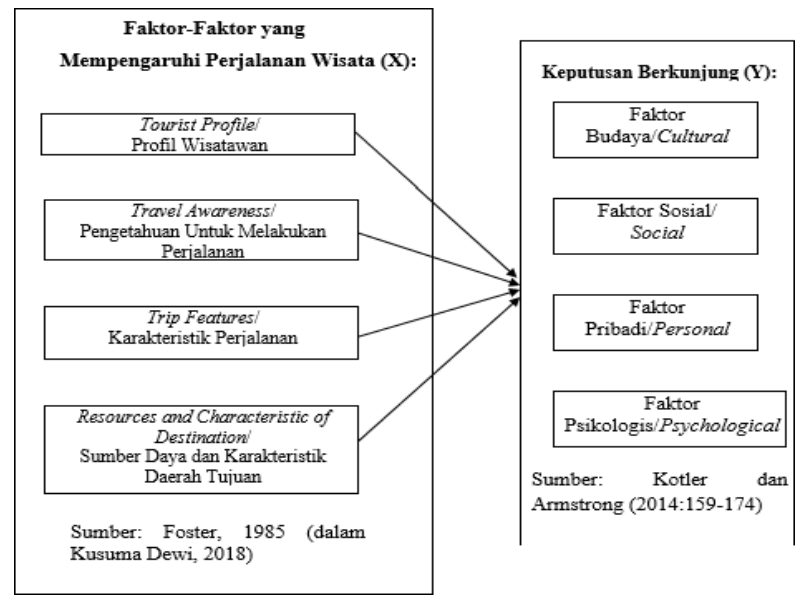

\section{METODOLOGI}

arikunto menyebutkan pengertian dari teknik pengumpulan data adalah bagaimana atau cara yang digunakan oleh pihak peneliti dalam proses melakukan pengumpulan data dalam proses penelitiannya. berdasarkan pernyataan tersebut dapat dikatakan bahwa metode penelitian adalah cara yang digunakan untuk mengumpulkan data yang diperlukan selama dalam proses penelitian

Penyusunan penelitian yang penulis gunakan adalah sebagai berikut:

\section{Data Primer}

Data primer adalah data yang dikumpulkan sendiri oleh peneliti langsung dari sumber awal ataupun informasi yang diperoleh secara langsung dari sumber asli, tidak lewat media perantara, diperoleh dengan menyebarkan kuesioner kepada responden (Sangaji, 2010). Informasi Primer yang bisa diteliti untuk riset ini bersumber dari:

\section{a. Observasi}

Sutrisno Hadi (dalam Sugiyono, 2012) mengatakan jika, observasi ialah proses yang kompleks, sesuatu proses yang tersusun dari bermacam proses biologis serta psikologis. 2 diantara yang terutama merupakan prosesproses pengamatan serta ingatan seorang peneliti.

Observasi itu sendiri Ialah pengumpulan informasi yang dicoba dengan metode turun langsung ke lokasi riset dengan metode pengamatan serta pencatatan gejala- indikasi yang nampak pada objek riset yang penerapannya langsung pada tempat di mana sesuatu kejadian, kondisi, ataupun suasana tengah terjadi.

b. Wawancara Menurut Sugiyono (2014) interview (wawancara) digunakan sebagai metode pengumpulan informasi apabila peneliti mau melaksanakan riset pendahuluan untuk menciptakan kasus yang wajib diteliti, serta pula apabila peneliti mau mengenali halhal dari responden yang lebih mendalam serta jumlah respondennya sedikit/ kecil.

c. Kuesioner (angket)

Kuesioner ataupun angket merupakan metode pengumpulan informasi lewat formulirformulir yang berisi pertanyaan yang diajukan secara tertulis pada seorang ataupun sekumpulan orang untuk menemukan jawaban ataupun asumsi serta data yang dibutuhkan oleh periset (Mardalis, 2010). Menurut Sugiyono (2017), skala likert merupakan skala yang digunakan untuk mengukur sikap, pendapat, dan persepsi seseorang atau sekelompok orang tentang fenomena sosial.

Dalam menjawab skala likert ini, responden hanya member tanda, misalnya checklist atau tanda silang pada jawaban yang dipilih sesuai pernyataan. Kuesioner yang telah di isi responden perlu dilakukan penyekoran. 
Pada penelitian ini, peneliti menggunakan kuesioner tertutup yang dimana penulis membatasi responden dengan menyediakan jawaban sehingga responden hanya perlu memilih melalui googleform untuk menghemat waktu dan biaya. Peneliti juga sudah menentukan kemungkinan jawaban sehingga responden hanya dapat memilih satu jawaban yang terdapat dalam daftar pilihan dan tidak dapat menulis jawabannya sendiri diluar dari pilihan jawaban yang telah disediakan.

\section{Data Sekunder}

Menurut Sugiyono (2017), data sekunder adalah sumber data yang tidak langsung memberikan data kepada pengumpul data. Data sekunder ini merupakan data yang sifatnya mendukung keperluan data primer seperti buku-buku, literatur dan bacaan yang berkaitan dan menunjang penelitian ini. Data sekunder pada penelitian bersumber pada:

Studi Pustaka

Menurut Danang Sunyoto (2016), studi kepustakaan (library research) adalah teknik pengumpulan data dengan mempelajari buku- buku yang ada hubungannya dengan obyek penelitian atau sumber-sumber lain yang mendukung penelitian.

Dalam penelitian ini, penulis lebih banyak membaca buku, artikel, jurnal, serta beberapa skripsi terdahulu yang berkaitan dengan topic penelitian untuk dijadikan sumber yang relevan.

Riset Internet (Online Research)

Teknik pengumpulan data yang berasal dari situs-situs atau website yang berhubungan dengan berbagai informasi yang dibutuhkan dalam penelitian.

\section{Dokumentasi}

Dokumentasi merupakan catatan peristiwa yang sudah berlalu, dapat berbentuk tulisan, gambar atau karya-karya monumental seseorang. Doukumen yang berbentuk tulisan misalnya catatan harian, sejarah kehidupan, biografi, peraturan, dan kebijakan. Dokumen yang berbentuk gambar misalnya foto, gambar hidup, sketsa, dan lain-lain. Studi dokumentasi merupakan pelengkap dari penggunaan metode observasi dan wawancara (Sugiyono, 2017).

\section{RESULT AND DISCUSSION}

Pengolahan data untuk penelitian ini adalah peneliti menggunakan alat bantu statistik, yaitu perangkat lunak SPSS (Statistical Packagefor the Social Science). Analisis data dimulai menggunakan dua langkah, yaitu pertama menggunakan uji validitas dan kedua menggunakan uji reliabilitas. Kedua langkah pengujian ini dilakukan terhadap seluruh pertanyaan kuesioner dengan menyerbarkan kuesioner sehingga dapat menentukan kelayakan kuesioner tersebut.

Jika butir-butir pertanyaan kuesioner hasilnya valid dan reliabel, maka kuesioner ini layak untuk digunakan. Namun, jika hasilnya tidak valid dan tidak reliabel, maka kuesioner tersebut wajib untuk direvisi sampai semua pertanyaan yang ada pada kuesioner tersebut menjadi valid dan reliabel.

Informasi yang sudah terkumpul berikutnya akan diolah lagi dan yang setelah itu akan disajikan dalam sebuah struktur yang apik serta benar. Informasi hasil kuesioner setelah itu diolah guna memperoleh nilai persentase. Adapun Tahap - tahap pengelolaannya merupakan bagaikan berikut (Gulo, 2010):

\section{Penyuntingan}

Seluruh informasi kuesioner yang sudah dikumpulkan baik secara online ataupun fisik. Berikutnya hendak diperiksa terlebih dulu setelah itu dikelompokkan bersumber pada tipe serta variabelnya. 


\section{Pemberian Kode}

Umumnya untuk tiap variable diberi kode dengan huruf, serta informasi diberi kode dengan angka. Penanda untuk tiap variable diberi indeks cocok dengan variabel yang bersangkutan. Informasi untuk tiap variabel/ indicator diberi kode angka dengan mencermati skala pengukuran pada variabel yang bersangkutan. Karna itu angka- angka yang dipakai untuk kode sebaiknya diberi pemahaman agar lebih jelas lagi, dengan nilai terendah satu.

3. Penataan serta Perhitungan Data

Penataan serta perhitungan informasi dicoba secara manual dengan memakai perlengkapan bantu yaitu Microsoft excel.

4. Tabulasi

Informasi yang sudah disusun serta dihitung, berikutnya akan diberikan dengan bentuk tabel. Pembuatan table tersebut dicoba dengan metode tabulasi langsung, hal ini dikarenakan informasi langsung dipindahkan dari informasi kekerangka tabel yang sudah disiapkan tanpa proses perantara yang lain.

5. Pengujian hasil informasi, melaksanakan pengujian validitas serta reliabilitas terhadap informasi yang telah dikumpulkan apakah dapat digunakan untuk dipakai dalam uji lapangan.

6. Mendeskripsikan informasi, menjabarkan hasil informasi baik dengan menggunakan tabel frekuensi ataupun diagram dan pengolahannya ditujukan untuk untuk menguasai dan memahami karakteristik informasi sampel riset.

7.Pengujian hipotesis, pengujian atas proporsi- proporsi yang sudah dibuat.

Uji Asumsi Klasik

Uji Normalitas

Apabila informasi hasil perhitungan onesample Kolmogorov- Smirnov menciptakan nilai diatas 0,05 , hingga model regresi penuhi anggapan normalitas( Ghozali, 2016).
Tabel Hasil Uji Normalitas

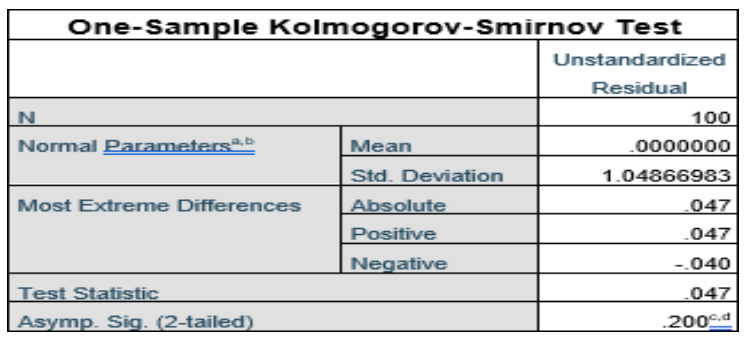

Berdasarkan data diatas, menunjukkan angka 0,200 yang dapat diartikan bahwa data diatas lebih besar dari 0,05 dan dapat dinyatakan berdistribusi normal.

Uji Heteroskedastisitas

Cara mengetahui cara kerja uji heteroskedastisitas adalah dengan melihat grafik plot antara nilai prediksi variable dependen dengan residualnya dan melihat apakah ada pola tertentu pada grafik scater plot. Jika ditemukan sebuah pola tertentu, seperti titik-titik yang ada membentuk polapola yang teratur maka ini adalah indicator telah terjadi heteroskedastisitas, jika tidak ditemukannya pola yang jelas, serta titik-titik tampak menyebar diatas dan dibawah angka 0 pada sumbu $Y$, dapat disimpulkan terjadi heteroskedastisitas (Ghozali, 2016).

\section{Gambar Uji Heteroskedastisitas}

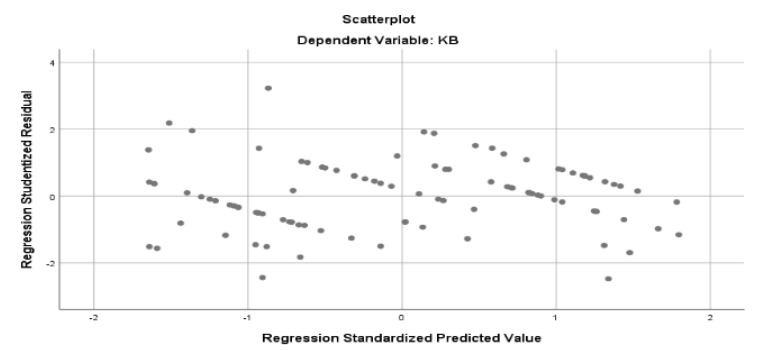

Gambar Scatter Plot diatas menunjukkan, dapat dilihat bahwa lingkaran- lingkarankecil yang menyebar dan tidak membentuk pola tertentu. Oleh karena itu, dapat disimpulkan bahwa data bersifatbaik dan menyebar 
sehingga tidak menyebabkan terjadinya heteroskedastisitas.

Analisis Regresi Linier Berganda

Sugiyono (2014) mengatakan dalam teorinya bahwa analisis regresi linier berganda memiliki tujuan untuk meramalkan bagaimana keadaan atau naik turunnya variabel dependen (kriterium), jika ada dua atau lebih variabel independen sebagai faktor prediator dimanipulasi (dinaik turunkan nilainya). Maka dapat disimpukan bahwa analisis regresi berganda sebaiknya dilakukan jika jumlah variabel independennya ada minimal 2 . Sugiyono (2014) dalam teorinya juga mengatakan, adapaun persamaan regresi linier berganda yang ditetapkan adalah seperti dibawah ini:

$Y=a+b_{1} X_{1}+b_{2} X_{2}+b_{3} X_{3}+b_{4} X_{4}+\varepsilon$

Keterangan:

$\mathrm{Y}=$ Keputusan Berkunjung

$\mathrm{a}=$ Koefisien Konstanta

b1,b2,b3... = Koefisien Regresi

$\mathrm{X} 1$ = Profil Wisatawan (Tourist Profile)

$\mathrm{X} 2=$ Pengetahuan Untuk Melakukan

Perjalanan (TraveAwareness)

X3 = Karakteristik Perjalanan (Trip Features)

X4 = Sumber Daya dan Karakteristik Daerah

Tujuan (Resources and Characteristic of

Destination)

$\varepsilon=$ Error, variabelgangguan

$\mathrm{Y}=1,788+(-0,490) \mathrm{X}_{1}+0,010 \mathrm{X}_{2}+(-$

$0,058) \mathrm{X}_{3}+0,010 \mathrm{X}_{4}$

\section{Tabel Uji Regresi LinierBerganda}

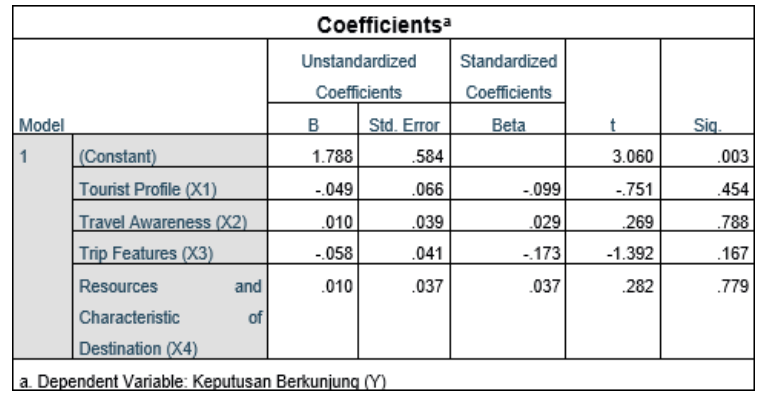

Dari persamaan regresi linier tersebut dapat diartikan:

1. Konstanta sebesar 1,788 secara matematis dapat dinyatakan bahwa jika nilai variabel bebas $(\mathrm{X})=0$, maka nilai variabel terikat (Y) adalah 1,788. Sehingga dapat diartikan bahwa nilai volume Keputusan Berkunjung Museum Tekstil Jakarta tanpa Faktor-Faktor yang Mempengaruhi Perjalanan Wisata adalah sebesar 1,788.

2. Koefisien regresi Tourist Profile (X1)sebesar -0,049 memiliki arah yang berlawanan, dapat diartikan jika nilai variabel lain tetap dan nilai variabel Tourist Profile (X1) bertambah 1, dari data tersebut disimpulan baha keputusan untuk Berkunjung (Y) akan terjadi penurunan sebanyak 0,049, berlaku juga kepada sebalikanya ketika Keputusan untuk Berkunjung (Y) ada peningkatan maka peningkatan atau kenaikan akan sebesar 0,049.

3. Koefisien regresi Travel Awareness (X2) sebesar 0,010 dapat diartikan jika variabel lain tetap dan nilai dari variabel Travel Awareness (X2) bertambah 1, maka KeputusanBerkunjung (Y) akan mengalami kenaikan sebesar 0,010, begitu juga sebaliknya jika Keputusan Berkunjung (Y) mengalami penurunan maka penurunan akan sebesar 0,010.

4. Koefisien regresi Travel Awareness (X3)sebesar -0,058 memiliki arah yang berlawanan, dapat diartikan jika nilai variabel lain tetap dan nilai variabel Travel Awareness.

5. (X3) bertambah 1, maka Keputusan Berkunjung (Y) akan terjadi penurunan sebesar 0,058, begitu juga sebaliknya jika Keputusan Berkunjung (Y) terjadi adanya kenaikan maka kenaikan akan sebesar 0,058 .

6.Koefisien regresi Resources and Characteristic of Destination (X4) sebesar 0,010 dapat diartikan jika variabel lain tetap 
Sadar Wisata: Jurnal Pariwisata

(p- ISSN 1858-0112, e-ISSN 15537-37677)

dan nilai dari variabel Travel Awareness (X2) bertambah 1, maka Keputusan Berkunjung (Y) akan mengalami kenaikan sebesar 0,010, begitu juga sebaliknya jika Keputusan Berkunjung (Y) mengalami penurunan maka penurunan akan sebesar 0,010 .

Uji Hipotesis

\section{Uji T}

Hasil hipotesis thitung jika dibandingkan dengan $t_{\text {tabel }}$ dengan ketentuan seperti dibawah ini :

a. Jika $\mathrm{t}_{\text {hitung }}>\mathrm{t}_{\text {tabel }}$ pada $\alpha=5 \%$ maka $\mathrm{H}_{0}$ ditolak dan $\mathrm{H}_{1}$ diterima (berpengaruh).

b. Jika $t_{\text {hitung }}<t_{\text {tabel }}$ pada $\alpha=5 \%$ maka $\mathrm{H}_{0}$ diterima dan $\quad \mathrm{H}_{1}$ ditolak (tidakberpengaruh).

Dalam penelitian ini untuk menentukan nilai $t_{\text {tabel }}$ sebagai batas daerah penerimaan atau penolakan hipotesis sebagai berikut :

Keterangan :

Tarafsignifikan $\alpha=0,05(5 \%)$

$\mathrm{n}=$ jumlahresponden

$\mathrm{k}=$ jumlahvariabel (bebas)

tabel: $0,05 / 2=0,025 ; 100-4-1=95$;

diperoleh ttabelsebesar 1,98525 .

\section{Tabel Hasil Uji T}

\begin{tabular}{|c|c|c|c|c|c|c|}
\hline \multicolumn{7}{|c|}{ Coefficients $^{a}$} \\
\hline \multirow{2}{*}{\multicolumn{2}{|c|}{ Model }} & \multicolumn{2}{|c|}{$\begin{array}{c}\text { Unstandardized } \\
\text { Coefficients }\end{array}$} & \multirow{2}{*}{$\begin{array}{c}\begin{array}{c}\text { Standardized } \\
\text { Coefficients }\end{array} \\
\text { Beta } \\
\end{array}$} & \multirow[b]{2}{*}{$t$} & \multirow[b]{2}{*}{ Siq. } \\
\hline & & B & Std. Error & & & \\
\hline \multirow[t]{5}{*}{1} & (Constant) & 2.024 & .964 & & 2.100 & .038 \\
\hline & Tourist Profile (X1) & .231 & .108 & .176 & 2.137 & .035 \\
\hline & Travel Awareness (X2) & .180 & .064 & .195 & 2.834 & .006 \\
\hline & Trip Features (X3) & .274 & .068 & .314 & 4.016 & .000 \\
\hline & \begin{tabular}{|lr} 
Resources & and \\
Characteristic & of \\
Destination $(X 4)$ &
\end{tabular} & .256 & .061 & .341 & 4.177 & .000 \\
\hline
\end{tabular}

Berdasarkan tabel hasil output SPSS diatas, cara pengambilan keputusan uji parsial pada dimensi faktor-faktor yang mempengaruhi wisatawan dapat diartikan sebagai:

1. Dimensi Profil Wisatawan/Tourist Profile (X1) memiliki thitung2,137> tabel 1,98525, maka $\mathrm{H}_{0}$ ditolak dan $\mathrm{H}_{1}$ diterima.
Volume 3 No.2 Desembar Tahun 2020

http://jurnal.unmuhiember.ac.id/index.php/wisata
Nilai signifikansi pada dimensi Profil Wisatawan/Tourist Profile (X1) sebesar $0,035<0,05$, maka $\mathrm{H}_{0}$ ditolak dan $\mathrm{H}_{1}$ diterima. Dapat disimpulkan Profil Wisatawan/Tourist Profile mempunyai pengaruh secara signifikan terhadap keputusan berkunjung wisatawan ke Museum Tekstil Jakarta.

Berdasarkan hasil perhitungan diatas, indikator-indikator dari dimensi Profil Wisatawan/Tourist Profile (X1) yakni umur, pendidikan dan tingkat pendapatan berpengaruh secara parsial terhadap Keputusan Berkunjung ke Museum Tekstil Jakarta.

2. Dimensi Pengetahuan Untuk Melakukan

Perjalanan/Travel Awareness

memiliki thitung2,834 > tabel 1,98525, maka $\mathrm{H}_{0}$ ditolak dan $\mathrm{H}_{1}$ diterima. Nilai signifikansi pada dimensi Pengetahuan Untuk Melakukan Perjalanan/Travel Awareness (X2) sebesar 0,006 $<0,05$, maka $\mathrm{H}_{0}$ ditolak dan $\mathrm{H}_{1}$ diterima. Dapat disimpulkan Pengetahuan Untuk Melakukan Perjalanan/Travel Awarenessmempunyai pengaruh secara signifikan terhadap keputusan berkunjung wisatawan ke Museum Tekstil Jakarta.

Berdasarkan hasil perhitungan diatas, indikator-indikator dari dimensi Pengetahuan Untuk Melakukan Perjalanan/Travel Awareness (X2) yakni adanya info mengenai tentang daerah tujuan wisata, ketersediaan fasilitas dan pelayanan yang dimiliki dan diberikan oleh Museum Tekstil Jakarta sudah baik.

3. Dimensi Karakteristik Perjalanan/Trip Features (X3) memiliki thitung4,016 > $\mathrm{t}_{\text {tabel }}$ 1,98525, maka $\mathrm{H}_{0}$ ditolak dan $\mathrm{H}_{1}$ diterima. Nilai signifikansi pada dimensi Karakteristik Perjalanan/Trip Features (X3)sebesar 0,000 < 0,05, maka $\mathrm{H}_{0}$ ditolak dan $\mathrm{H}_{1}$ diterima. Dapat disimpulkan bahwa Karakteristik Perjalanan / Trip Features mempunyai pengaruh secara 
signifikan terhadap keputusan berkunjung wisatawan ke Museum Tekstil Jakarta.Berdasarkan hasil perhitungan diatas, indikator-indikator dari dimensi Karakteristik Perjalanan/Trip Features (X3) yakni jarak, biaya dan waktu perjalanan berpengaruh secara parsial terhadap Keputusan Berkunjung di Museum Tekstil Jakarta.

4. Dimensi Sumber Daya dan Karakteristik Daerah Tujuan/Resources and Characteristic of Destination (X4) memiliki thitung4,177 > $t_{\text {tabel }} 1,98525$, maka $\mathrm{H}_{0}$ ditolak dan $\mathrm{H}_{1}$ diterima. Nilai signifikansi pada dimensi Sumber Daya dan Karakteristik Daerah Tujuan/Resources and Characteristic of Destination (X4)sebesar $0,000<0,05$, maka $\mathrm{H}_{0}$ ditolak dan $\mathrm{H}_{1}$ diterima. Dapat disimpulkan Sumber Daya dan Karakteristik Daerah Tujuan/Resources and Characteristic of Destination mempunyai pengaruh secara signifikan terhadap keputusan berkunjung wisatawan ke Museum Tekstil Jakarta.

Berdasarkan hasil perhitungan diatas, indikator-indikator dari dimensi Sumber Daya dan Karakteristik Daerah Tujuan/Resources and Characteristic of Destination (X4) yakni jenis atraksi, ketersediaan dan kualitas fasilitas, ketersediaan dan kualitas pelayanan, serta kondisi lingkunganyang dimiliki oleh Museum Tekstil Jakarta sudah baik. Uji F

Uji statistik $F$ mempunyaisignifikansi 0,05. Kriteria pengujian hipotesis dengan menggunakan statistic $F$ adalah jika nilai signifikansi $\mathrm{F}<0,05$, maka hipotesis alternative diterima, yang menyatakan bahwa semua variable independen secara simultan dan signifikan mempengaruhi variable dependen (Ghozali, 2016) dengan rumus:
$\mathrm{DF} 1=\mathrm{k}-1$

$\mathrm{DF} 2=\mathrm{n}-\mathrm{k}$

DF $1=4-1=3$

$\mathrm{DF} 2=100-4=96$

$\mathrm{f}_{\text {tabel }}=3 ; 96=2,70$

\section{Tabel Hasil Uji F}

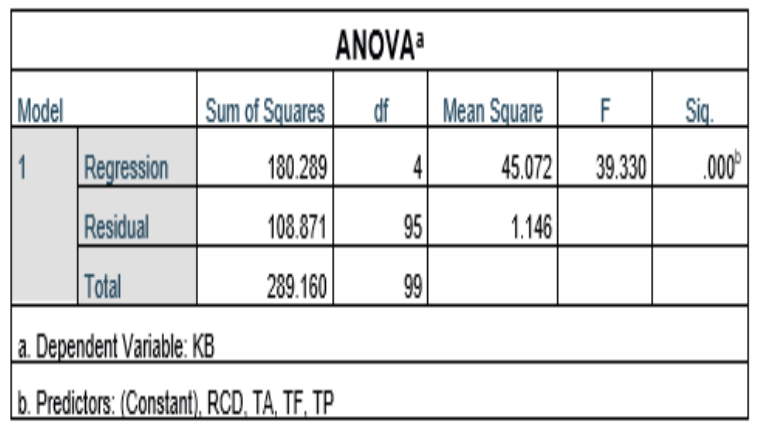

Dari tabel ANOVA diatas dapat diartikan bahwa sig. $0,000<0,05$. $\mathrm{f}_{\text {hitung }}$ menunjukkan angka 39,330 yang dimana $>f_{\text {tabel }} 2,70$. Maka dapat disimpulkan bahwa $\mathrm{H}_{0}$ ditolak dan $\mathrm{H}_{1}$ diterima, artinya dimensiProfil Wisatawan/Tourist Profile, Pengetahuan Untuk Melakukan Perjalanan/Travel Awareness, Karakteristik Perjalanan/Trip Features, serta Sumber Daya dan Karakteristik Daerah Tujuan/Resources and Characteristic of Destination secara simultan mempunyai pengaruh secara signifikan terhadap keputusan berkunjung wisatawan ke Museum Tekstil Jakarta.

Koefisien Determinasi $\left(\mathrm{R}^{2}\right)$

Berdasarkan penghitungan koefisien korelasi, dengan ditu dapat dikalkulasikan koefisien determinasi dengan rumus :

$R^{2}=R^{2} \times 100 \%$ 
Sadar Wisata: Jurnal Pariwisata

(p- ISSN 1858-0112, e-ISSN 15537-37677)

Tabel Koefisien Determinasi

\begin{tabular}{|l|r|r|r|r|}
\hline \multicolumn{5}{|c|}{ Model Summary } \\
\hline Model & \multicolumn{1}{|c|}{$\mathrm{R}$} & R Square & \multicolumn{1}{|c|}{$\begin{array}{c}\text { Adjusted R } \\
\text { Square }\end{array}$} & $\begin{array}{c}\text { Std. Error of the } \\
\text { Estimate }\end{array}$ \\
\hline 1 & $.790^{\circ}$ & .623 & .608 & 1.07052 \\
\hline \multicolumn{5}{|l|}{ a. Predictors: (Constant), RCD, TA, TF, TP } \\
\hline
\end{tabular}

Dari tabel diatas koefisien determinasi yang diperoleh adalah0,608 yang dapat diartikan sebanyak 60,8\% Keputusan Berkunjung (Y) dari pengunjung Museum Tekstil Jakarta dipengaruhi oleh variabel bebas $(\mathrm{X})$ yaitu Profil Wisatawan/Tourist Profile, Pengetahuan Untuk Melakukan Perjalanan/Travel Awarenes. Karakteristik Perjalanan/Trip Features, serta Sumber Daya dan Karakteristik DaerahTujuan/Resources and Characteristic of Destination. Sementara sisanya 39,2\% dijelaskan oleh variabel diluar variabel yang digunakan.

\section{KESIMPULAN}

Penelitan ini dilakukan dengan menggunakan rancangan kuantitatif, dimana penulis melakukan observasi, pengumpulan data dengan teknik penyebaran kuesioner secara tertutup kepada 100 responden. Peneliti menggunakan SPSS dan Microsoft Excel dalam mengolah data. Berdasarkan hasil penelitian dan analisis data yang telah dilakukan, dapat ditarik beberapa kesimpulan sebagai berikut:

1. Berdasarkan hasil uj it, dimensi Profil Wisatawan/Tourist Profile memiliki pengaruh terhadap keputusan berkunjung wisatawan ke Museum Tekstil Jakarta dengan nilai thitung $>t_{\text {tabel }}(2,137$

$>1,98525)$ dan nilai signifikansi $(0,000$
Volume 3 No.2 Desembar Tahun 2020

http://jurnal.unmuhjember.ac.id/index.php/wisata
$<0,05)$, maka hipotesis diterima. Hal ini disebabkan oleh wisatawan dalam memutuskan untuk berkunjung ke Museum Tekstil Jakarta dipengaruhi oleh umur, pendidikan, tingkat pendapatan, motivasi, sikap, dan keinginan wisatawan.

2. Berdasarkan hasil uji t, dimensi Pengetahuan Untuk Melakukan Perjalanan/Travel Awareness memiliki pengaruh terhadap keputusan berkunjung wisatawan ke Museum Tekstil Jakarta dengan nilai $t_{\text {hitung }}>t_{\text {tabel }}(2,834$

$>1,98525)$ dan nilai signifikansi $(0,006<0,05)$, maka hipotesis diterima. Hal ini disebabkan oleh wisatawan dalam memutuskan untuk berkunjung ke Museum Tekstil Jakarta dipengaruhi oleh info tentang tujuan wisata, ketersediaan fasilitas, dan ketersediaan pelayanan.

3. Berdasarkan hasil uji t, dimensi Karakteristik Perjalanan/Trip Features memiliki pengaruh terhadap keputusan berkunjung wisatawan ke Museum Tekstil Jakartadengannilaithitung $>t_{\text {tabel }}(4,016$ $>1,98525)$ dan nilaisignifikansi $(0,000<0,05)$, maka hipotesis diterima. Hal ini disebabkan oleh wisatawan dalam memutuskan untuk berkunjung ke Museum Tekstil Jakarta dipengaruhi oleh jarak, biaya, dan waktu perjalanan.

4. Berdasarka nhasil uji t,dimensi Sumber Daya dan Karakteristik Daerah Tujuan/Resources and Characteristic of Destination memiliki pengaruh terhadap keputusan berkunjung wisatawan ke Museum Tekstil Jakarta dengan nilaithitung $>t_{\text {tabel }}(4,177>1,98525)$ dan nilai signifikansi $(0,000<0,05)$, maka hipotesis diterima. Hal ini disebabkan oleh wisatawan dalam memutuskan untuk berkunjung ke Museum Tekstil Jakarta dipengaruhi oleh jenis atraksi, ketersediaan dan kualitas fasilitas, serta 
pelayanan dan kondisi lingkungan dari Museum Tekstil Jakarta.

5. Berdasarkanhasil uji f, maka dapat disimpulkan bahwa secara simultan dimensi Profil Wisatawan/Tourist Profile, Pengetahuan Untuk Melakukan Perjalanan/Travel Awareness, Karakteristik Perjalanan/Trip Features, serta Sumber Daya dan Karakteristik Daerah Tujuan/Resources and Characteristic of Destination dalam Faktor-Faktor Yang Mempengaruhi Perjalanan Wisata berpengaruh secara signifikan terhadap variable Keputusan Berkunjung di Museum Tekstil Jakarta dengan nilaif hitung $>f_{\text {tabel }}(39,330>2,70)$ dan nilai signifikansi $(0,000<0,05)$.

6. Hasil dari uji koefisien determinasi menunjukkan bahwa Faktor-Faktor Yang Mempengaruhi Perjalanan Wisata (X) member sumbangan pengaruh terhadap tingkat Keputusan Berkunjung (Y) di Museum Tekstil Jakarta sebanyak 60,8\%. Berdasarkan hasil penelitian ini, dapat disimpulkan bahwa faktor-faktor yang mempengaruhi wisatawan berkunjung ke Museum Tekstil Jakarta sangat penting. Hal ini dapat dijadikan sebagai bahan pertimbangan dalam melakukan perbaikan serta pengembangan Museum Tekstil Jakarta, baik untuk pihak pengelola museum maupun pihak pemerintah.

\section{SARAN}

Berdasarkan hasil penelitian mengenai faktor-faktor yang mempengaruhi perjalanan wisatawan ke Museum Tekstil Jakarta, berikut saran yang dapat peneliti berikan kepada pihak pengelola :

1. Berdasarkan hasil penelitian mengenai dimensi Profil

2. Wisatawan/Tourist Profile, Museum Tekstil Jakarta diharapkan dapat lebih meningkatkan kinerjanya agar lebih meningkatkan motivasi untuk berkunjung serta memenuhi keinginan dari wisatawan. Hal ini dikarenakan dimensi Profil Wisatawan/Tourist Profile dinilai paling rendah dibandingkan dimensi lainnya oleh responden, sehingga tidak adanya pengaruh yang cukup signifikan terhadap keputusan berkunjung.

4. Berdasarkan hasil yang diteliti mengenai dimensi Pengetahuan Untuk Melakukan Perjalanan/Travel Awareness, Museum Tekstil Jakarta diharapkan dapat lebih meningkatkan dari segi informasi untuk masyarakat melalui sosial media agar dapat menarik wisatawan untuk datang. Hal ini dikarenakan dimensi Pengetahuan Untuk Melakukan Perjalanan/Travel Awareness dinilai cukup rendah oleh responden, sehingga dinilai oleh peneliti tidak adanya pengaruh yang signifikan terhadap keputusan berkunjung.

5. Berdasarkan hasil penelitian mengenai dimensi Karakteristik Perjalanan/Trip Features, Museum Tekstil Jakarta diharapkan dapat mempertahankan faktor-faktor biaya serta jarak untuk menjangkau lokasi. Hal ini dikarenakan dimensi Karakteristik Perjalanan/Trip Features dinilai cukup tinggi oleh responden, sehingga berpengaruh secara signifikan terhadap keputusan berkunjung.

6. Berdasarkan hasil penelitian mengenai dimensi Sumber Daya dan Karakteristik Daerah Tujuan/Resources and Characteristic of Destination, Museum Tekstil Jakarta diharapkan dapat menambahkan jenis atraksi yang disajikan kepada pengunjung, ketersediaan dan kualitas dari fasilitas, serta pelayanan dan kondisi lingkungan yang dimiliki. Hal ini dikarenakan dimensi Karakteristik Daerah Tujuan/Resources and Characteristic of 
Destination dinilai paling tinggi dibandingkan dimensi lainnya oleh responden, sehingga berpengaruh secara signifikan terhadap keputusan berkunjung

\section{DAFTAR PUSTAKA}

Anggela, M. M., Karini, N. M., \& Sofia, N. M. (2017). Persepsi Dan Motivasi Wisatawan Yang Berkunjung Ke Daya Tarik Wisata Jembong Di Kabupaten Buleleng. Universitas Udayana .

Anwani, \& Lisfiyati, F. (2014). FaktorFaktor Yang Mempengaruhi Minat Wisatawan Berkunjung Di Pantai Glagah Indah Yogyakarta. STIE Pariwisata API Yogyakarta .

Astina, I. B. (2009). Analisis Pariwisata. Universitas Udayana .

-------(2013). Prosedur Penelitian: Suatu Pendekatan Praktik. Jakarta: Rineka Cipta.

$\begin{array}{cc}\text { Belajar } & \text { Membatik } \\ & \text { Museum,fromhttps://edukasi. }\end{array}$ kompas.com/read/2014/01/20 /1132456/Belajar.Membatik.d i.Museum.

Data Kunjungan Wisatawan Nusantara, from https://data.jakarta.go.id/dataset/dat a- kunjungan-wisatawan-nusantarake- destinasi-wisata-di-dki-jakarta.

Eero, N. (2013). Tourist Motivation and Information Search Behaviour Case: Museum of Contemporary Art Kiasma. Laurea University of Applied Sciences .

Ghozali, I. (2016). Aplikasi Analisis Multivariate dengan Program IBM SPSS 23. Semarang: BPFE Universitas Diponegoro.

Gulo, W. (2010). Metodologi Penelitian. Jakarta: PT Grasindo. Gujarati, D.
(2012). Dasar-dasar Ekonometrika. Jakarta: Salemba Empat.

Hair, J. F., \& E., a. A. (2010).

Multivariate Data Analysis. New Jersey: Pearson Prentice Hall.

Hermansyah, D., \& Waluya, B. (2012). Analisis Faktor- Faktor Pendorong Motivasi Wisatawan Nusantara Terhadap Keputusan Berkunjung Ke Kebun Raya Bogor. Bogor: Manajemen Pemasaran Pariwisata FPIPS UPI.

Irwan, K. (2010). Potensi Objek Wisata Sebagai Daya Tarik Wisata. Yogyakarta: Kertas Karya.

Kotler, \& Keller. (2009). Manajemen Pemasaran. Jilid I. Edisi ke 13. Jakarta: Erlangga.

Lestari, A., \& Sunarti. (2016). Analisis Pengembangan Promosi Dalam Upaya Menarik Kunjungan Wisatawan. Universitas Brawijaya.

Mahadewi, N. M. (2012). Atraksi,Produk Wisata Dan Event Wisata Dari Teori Ke Praktik. Sekolah Tinggi Pariwisata Nusa Dua Bali .

Mengenal Kain Nusantara di Museum Tekstil, Ikut Menjaga Warisan Budaya Nusantara, from https://wartakota.tribunnews. com/2019/11/05/mengenal- kainnusantara-di-museum- tekstil-ikutmenjaga-warisan- budayanusantara. 
Museum

Tekstil, https://www.jakartamrt.co.id/petadistrik/museum-tekstil/

Museum

Tekstil, from https://www.jakarta.go.id/artikel/25 3 8/museum-tekstil/

R, B., \& Rozak, H. A. (2012). Kualitas Daya Tarik Wisata, Kepuasan dan Niat Kunjungan Kembali Wisatawan Mancanegara Di jawa Tengah. Universitas Stikubank Semarang .

Meyers, Koen. 2009. Pengertian Pariwisata, Jakarta: Unesco Office. Muhammad, F. (2009). Metode Penelitian Kuantitatif, Sebuah Pengantar. Semarang: Walisongo Press.

Sangaji, E. M. (2010). Metodologi Penelitian. Yogyakarta: ANDI.

Septiawan, F. (2016). Motivasi Wisatawan Berkunjung Ke Taman Merdeka Metro Tahun 2016 . Universitas Lampung .

Setiawan, L., \& Suryasih, I. A. (2016). Karakteristik Dan Persepsi Wisatawan Terhadap Daya Tarik Wisata Pantai Kata Di Kota Pariaan,Sumatera Barat. Universitas Udayana .

Siregar, S. (2013). Metode Penelitian Kuantitatif Dilengkapi Dengan Perbandingan Perhitungan Manual \& SPSS. Jakarta: Penada Media Group.
Sugiarto, P. D., Hendratono, D. T., \& Sudibyo, D. (2015). Metodologi Penelitian Hospitaliti \& Pariwisata. Tangerang: PT Matana Publishing Utama.

Sugiyono. (2014). Metode Penelitian Pendidikan Pendekatan Kuantitatif, Kualitatif Dan R\&D. Bandung: Alfabeta.

Suharsimi, A. (2016). Prosedur Penelitian: Suatu Pendekatan Praktik. Jakarta: Rineka Cipta.

Sujarweni, W. V. (2014). Metode Penelitian: Lengkap, Praktis, dan Mudah Dipahami. Yogyakarta: Pustaka Baru Press

Sulaeman, A. (2018). Analisis Pengaruh Kualitas Pelayanan Dan Produk Terhadap Kepuasan Pelanggan Pada Pt.Cakrawala Citramega. (D. F. Pamulang, Ed.)

Suwena, I. K., \& Widyatmaja, I. G. (2017). Pengetahuan Dasar Ilmu Pariwisata. Pustaka Larasan.

Usman, H., \& Purnomo, A. (2009). Metodologi Penelitian Sosial. Jakarta: Bumi Aksara.

Yuliani. (2013). Strategi Komunikasi Dinas Kebudayaan Pariwisata Dan Kominfo (Disbudpar) Dalam Meningkatkan Kunjungan Wisatawan Di Desa Pampang Kota Samarinda. Universitas Mulawarman. 